\title{
Phylogenetic Information Content of Copepoda Ribosomal DNA Repeat Units: ITS1 and ITS2 Impact
}

\author{
Maxim V. Zagoskin,, ${ }^{1}$ Valentina I. Lazareva, ${ }^{2}$ Andrey K. Grishanin, ${ }^{2,3}$ and Dmitry V. Mukha ${ }^{1}$ \\ ${ }^{1}$ Vavilov Institute of General Genetics, Russian Academy of Sciences, Gubkin Street. 3, Moscow 119991, Russia \\ ${ }^{2}$ Papanin Institute for Biology of Inland Waters, Russian Academy of Sciences, Borok 152742, Russia \\ ${ }^{3}$ Dubna International University for Nature, Society and Man, Universitetskaya Street 19, Dubna 141980, Russia
}

Correspondence should be addressed to Maxim V. Zagoskin; zagoskinmv@gmail.com, Andrey K. Grishanin; andreygrishanin@mail.ru and Dmitry V. Mukha; dmitryVmukha@gmail.com

Received 23 April 2014; Revised 8 July 2014; Accepted 8 July 2014; Published 18 August 2014

Academic Editor: Peter F. Stadler

Copyright ( $) 2014$ Maxim V. Zagoskin et al. This is an open access article distributed under the Creative Commons Attribution License, which permits unrestricted use, distribution, and reproduction in any medium, provided the original work is properly cited.

\begin{abstract}
The utility of various regions of the ribosomal repeat unit for phylogenetic analysis was examined in 16 species representing four families, nine genera, and two orders of the subclass Copepoda (Crustacea). Fragments approximately 2000 bp in length containing the ribosomal DNA (rDNA) $18 \mathrm{~S}$ and $28 \mathrm{~S}$ gene fragments, the $5.8 \mathrm{~S}$ gene, and the internal transcribed spacer regions I and II (ITS1 and ITS2) were amplified and analyzed. The DAMBE (Data Analysis in Molecular Biology and Evolution) software was used to analyze the saturation of nucleotide substitutions; this test revealed the suitability of both the 28S gene fragment and the ITS1/ITS2 rDNA regions for the reconstruction of phylogenetic trees. Distance (minimum evolution) and probabilistic (maximum likelihood, Bayesian) analyses of the data revealed that the $28 \mathrm{~S}$ rDNA and the ITS1 and ITS2 regions are informative markers for inferring phylogenetic relationships among families of copepods and within the Cyclopidae family and associated genera. Split-graph analysis of concatenated ITS1/ITS2 rDNA regions of cyclopoid copepods suggested that the Mesocyclops, Thermocyclops, and Macrocyclops genera share complex evolutionary relationships. This study revealed that the ITS1 and ITS2 regions potentially represent different phylogenetic signals.
\end{abstract}

\section{Introduction}

Copepods are important components of zooplankton and the food chain in marine and freshwater ecosystems. The subclass Copepoda is believed to contain approximately 13,000 morphospecies; however, the actual number of species in this subclass might be much greater [1]. The majority of the freshwater copepod species belong to the order Cyclopoida, which includes the free-living species (approximately 800) in the family Cyclopidae. The other two free-living families (Oithonidae and Cyclopinidae) contain mainly marine species except for a few species in Oithonidae [2].

Systematic analyses of cyclopoid copepods (order Cyclopoida) have primarily focused on morphological characteristics [2-8], and the majority of molecular studies have targeted marine copepods [9-41]. The phylogenetic history of freshwater cyclopoid copepods is not well understood. A few studies on Cyclopidae have used molecular and morphological analyses on the Mesocyclops genus (Crustacea: Cyclopidae) [42], E. serrulatus group [43], Acanthocyclops vernalisrobustus species complex $[44,45]$, and 11 populations of Macrocyclops albidus [46]; other phylogenetic analyses have focused only on molecular markers in Diacyclops spp., which are found in western Australia [47] and Lake Baikal [48].

Molecular markers such as genomic DNA fragments are used for phylogenetic analyses to elucidate the evolutionary history of living organisms, and the region of genomic DNA analyzed is critical. Mitochondrial DNA fragments (genes encoding the cytochrome $c$ oxidase subunit I (COI), 16S rRNA, and cytochrome b) [9-21, 39, 40, 49-52] and/or nuclear rDNA regions have been used for the phylogenetic analysis of cyclopoid copepods [22-37, 41, 53-58]. Mitochondrial DNA fragments might be less useful for the analysis of copepod phylogeny compared to the phylogeny of other 


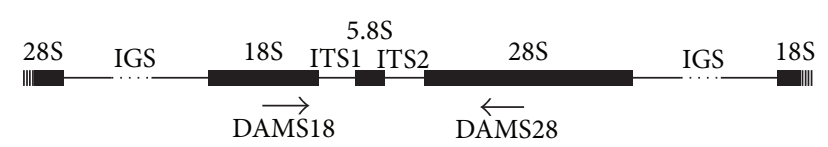

FIGURE 1: Organization of eukaryotic tandemly repeated rDNA clusters. 18S, 5.8S, and 28S ribosomal RNA genes; ITS1 and ITS2 internal transcribed spacers; IGS intergenic spacer. Arrows indicate the locations of the DAMS18 and DAMS28 primers.

taxa; furthermore, amplification of COI is difficult in some copepods [59-61]. However, these DNA fragments might be informative for analyses of population differentiation or cryptic speciation $[9,11-15,38-40,50,52]$. Therefore, comparison of nuclear rDNA regions might be informative for the phylogenetic analysis of copepods.

In most eukaryotes, rRNA genes are located in a multigene family of genomic clusters of repeated sequences. Within these clusters, the 18S, 5.8S, and 28S rRNA genes are separated by internal transcribed spacers (ITS1 and ITS2) and an intergenic spacer [62] (Figure 1). Ribosomal DNA (rDNA) is a reliable and informative phylogenetic marker [63] that contains sequences with different rates of evolutionary variability. In most eukaryotes, the most evolutionarily conserved genes are the rRNA genes; comparison of their sequences allows estimation of the evolutionary distances at intergeneric and higher taxonomic levels. Comparison of the more evolutionarily variable spacer sequences enables the study of phylogenetic relationships at the species and population levels [63-65]. Therefore, comparison of different regions of rDNA enables the phylogenetic analysis of organisms over extended evolutionary distances.

Phylogenetic relationships among cyclopoid copepods at higher systematic levels (ordinal, familial, and generic) have been resolved using the $18 \mathrm{~S}$ and $28 \mathrm{~S}$ nuclear rRNA genes [28, 29,55-57], and the relationships at the lower taxonomic levels (species and populations) have been resolved using the ITS2 of the nuclear rDNA gene cluster [30, 40, 42, 52, 58].

Notably, analysis of the evolutionary history of living organisms based on only one molecular marker can uncover bifurcating phylogenetic trees, revealing branched evolution. However, it recently becomes evident that evolution is not always tree-like. Comparisons of gene trees based on different genetic loci often reveal conflicting tree topologies. These discrepancies are not always due to the problems with the sampling and the gene tree reconstruction methods. Reticulation events such as horizontal gene transfer (HGT) and hybridization may be responsible for contradictions in lineages. During an HGT event, a DNA segment is transferred from one organism to another which is not its offspring, whereas hybridization describes the origin of a new species through an interspecies mating. Both processes yield genomes that are mixtures of DNA regions derived from different species. Consequently, evolutionary relationships between species whose past includes reticulation can often be better represented by using phylogenetic networks rather than trees [65-67].
In view of the above, comparing phylogenetic trees based on different molecular markers may be used for the analysis of evolutionary events caused by reticulate evolution. Phylogenetic signals from various molecular markers are potentially divergent during reticulate evolution, resulting in phylogenetic trees with alternative positions for the individual branches [68-71]. Comparative analysis of the rDNA ITS1 and ITS2 sequences is suitable for studying phylogenetic relationships in terms of branching and reticulate evolution $[63,68,70,72-82]$.

Reticulate evolution is primarily driven by hybrid speciation, which is common among plants [83] but also occurs among animals, particularly including fish [84], amphibians, and several invertebrates [85-87]. In both mammals [88] and arthropods $[89,90]$, a single instance of hybrid speciation has been well described. Interspecies hybridization typically results in complicated relationships within species complexes, characterized by indistinct species borders. Reticulate evolution among crustaceans has been observed only within species complexes of daphnids [91-94].

In this study, we analyzed the phylogenetic relationships within a small group of cyclopoid copepods representing several genera of freshwater (Cyclops, Thermocyclops, Diacyclops, Megacyclops, Macrocyclops, and Mesocyclops) and marine (Oithona and Paracyclopina) organisms. Specific freshwater species were selected for analysis because these species are important for the maintenance of food chains in Russian freshwater ecosystems. The aim of this study was to analyze the sequence characteristics of the rDNA 28S gene, ITS1, and ITS2 regions as phylogenetic markers for the selected group of organisms.

\section{Materials and Methods}

2.1. Samples Collection. Nine freshwater species of the Cyclopidae family were collected near the Borok settlement in the Yaroslavskaya region of Russia: Mesocyclops leuckarti (Claus, 1857), Cyclops strenuus (Fischer, 1851), and Cyclops insignis (Claus, 1857) (population no. 1) from the Barskiy Pond $\left(58^{\circ} 3^{\prime} 59.35^{\prime \prime} \mathrm{N}\right.$; $\left.38^{\circ} 15^{\prime} 10.16^{\prime \prime} \mathrm{E}\right)$; Thermocyclops oithonoides (Sars, 1863) from the Sunoga pond $\left(58^{\circ} 2^{\prime} 34.66^{\prime \prime} \mathrm{N} ; 38^{\circ} 14^{\prime} 41.29^{\prime \prime} \mathrm{E}\right)$; Thermocyclops crassus (Fischer, 1853), Macrocyclops distinctus (Richard, 1887), Macrocyclops albidus (Jurine, 1820), Diacyclops bicuspidatus (Claus, 1857), and Megacyclops viridis (Jurine, 1820) (population no. 1) from the Ikhteologichesky Canal $\left(58^{\circ} 3^{\prime} 55.62^{\prime \prime} \mathrm{N}\right.$; $38^{\circ} 15^{\prime} 21.05^{\prime \prime} \mathrm{E}$ ); and Megacyclops viridis (Jurine, 1820) (population no. 2) from a pond in the flood zone of the Rybinsk Reservoir $\left(58^{\circ} 4^{\prime} 4.70^{\prime \prime} \mathrm{N} ; 38^{\circ} 15^{\prime} 39.88^{\prime \prime} \mathrm{E}\right)$.

Cyclops kolensis (Lilljeborg, 1901) and Cyclops insignis (Claus, 1857) (population no. 2) were collected from the Andreevsky small pond in Vorob'evy Gory, Moscow, Russia $\left(55^{\circ} 42^{\prime} 35.40^{\prime \prime} \mathrm{N} ; 37^{\circ} 34^{\prime} 6.61^{\prime \prime} \mathrm{E}\right)$. Two marine species, Oncaea sp. (Claus) and Oithona similis (Claus, 1866), were collected from the Norwegian Sea $\left(68^{\circ} 52^{\prime} 36.67^{\prime \prime} \mathrm{N} ; 3^{\circ} 8^{\prime} 21.91^{\prime \prime} \mathrm{E}\right)$.

Individuals of each species were collected for further analysis at the specified locations over a 0.5 - to 1-hour period. 
No specific permission was required to collect samples at these locations. None of the studied species is endangered or protected.

A fragment of the $28 \mathrm{~S}$ gene from each of the four marine species Paracyclopina nana (Smirnov, 1935) (GenBank accession number FJ214952), Oithona nana (Giesbrecht, 1893) (GenBank accession number FM991727), Oithona simplex (Farran, 1913) (GenBank accession number AF385458), and Oithona helgolandica (Claus, 1863) (GenBank accession number FM991724.1) was also used for the analysis. The DNA was extracted from either samples preserved in $70 \%$ ethanol or raw materials (Moscow populations).

2.2. DNA Extraction, PCR Amplification, and Sequencing. The genomic DNA was isolated from 10-20 individuals of each collected species using the DNeasy Blood \& Tissue kit (QIAGEN, Hilden, Germany) according to the manufacturer's instructions and was frozen at $-20^{\circ} \mathrm{C}$. The rDNA region (approximately $2000 \mathrm{bp}$ ) was amplified from the genomic DNA by polymerase chain reaction (PCR) using the universal eukaryotic rDNA primers DAMS18 and DAMS28 [95-97] (Figure 1). The amplified rDNA regions contained the ITS1 (261-388 bp) and ITS2 (188-262 bp) regions, the $5.8 \mathrm{~S}$ gene $(157 \mathrm{bp})$, and approximately 200 and $1000 \mathrm{bp}$ of the $18 \mathrm{~S}$ and $28 \mathrm{~s}$ genes, respectively. The amplification was performed in $50 \mu \mathrm{L}$ reactions using a PCR Master Mix (2X) (Fermentas, Vilnius, Lithuania) according to the manufacturer's instructions; the reactions were performed in a Primus 25 advanced Thermocycler (PEQLAB, Erlangen, Germany) using previously published rDNA-specific parameters [98]. The PCR products were resolved on $1.0 \%$ agarose gels, and DNA was extracted from the observed unique bands using the QIAquick Gel Extraction Kit (QIAGEN, Hilden, Germany). The extracted products were cloned into the pGEM-T Easy vector (Promega, USA), and the resulting plasmids were used to transform Escherichia coli JM109 competent cells (Promega, USA) according to the manufacturer's instructions. For each species, the amplified product and five clones were sequenced. Automated sequences were generated on an ABI PRISM 310 Genetic Analyzer according to Sanger et al. [99] with a BigDye Termination kit (Applied Biosystems, USA). The sequences generated in this study were deposited in GenBank under the accession numbers KF153689-KF153701.

2.3. Phylogenetic Analyses. The rDNA sequences were aligned using ClustalW $2.1[100,101]$ with some manual adjustments. The boundaries of the ITS1 and ITS2 regions and the $28 \mathrm{~S}$ gene were identified by comparing the primerdelimited sequences against sequences in the GenBank database using BLAST analysis. The boundaries of the conserved sequences were considered to represent the 5.8S, $18 \mathrm{~S}$, and $28 \mathrm{~S}$ gene flanking regions if they were $100 \%$ similar to the boundaries of rDNA sequences in the GenBank database. The initial sequence alignment flanked by DAMS18/DAMS28 primers was divided into ITS1 and ITS2 alignments. The rDNA genetic distances were estimated using the MEGA V5.2 software [102]. DAMBE (Data Analysis in Molecular Biology and Evolution) software was used to analyze substitution saturation [103-105]. This method computes the entropy-based index of substitution saturation and its critical value. If the index of substitution saturation (Iss) approaches 1 or if the Iss is not smaller than the critical Iss value (Iss.c), then sequences are considered to contain substantial saturation. As is known, the substitution saturation decreases phylogenetic information contained in sequences and has plagued the phylogenetic analysis involving deep branches. In the extreme case when sequences have experienced full substitution saturation, the similarity between the sequences will depend entirely on the similarity in nucleotide frequencies, which often does not reflect phylogenetic relationships [106].

The rDNA-based phylogenetic trees were estimated using probabilistic (maximum likelihood (ML), Bayesian) and distance (minimum evolution (ME)) methods [107-110]. ML and ME analyses of ITS1, ITS2, and 28S data were performed using the program MEGA V5.2. Branch support was assessed using the bootstrap method [111] (1,000 replicates) with the close-neighbor-interchange (CNI) algorithm at a search level of 1 for ME analysis and heuristic search for ML analysis. The Bayesian information criterion (BIC), as implemented in MEGA V5.2, was used to identify the bestfit model of sequence evolution for the trees estimated using ML. The evolutionary history was inferred using the ML method based on the general time reversible with the gamma distribution shape parameter $(\mathrm{GTR}+\mathrm{G})$ model for $28 \mathrm{~S}$ and the Hasegawa-Kishino-Yano with gamma distribution shape parameter $(\mathrm{HKY}+\mathrm{G})$ model [112] for the ITS1, ITS2, and concatenated ITS1/ITS2 alignments. In addition to these methods, ITS1 and ITS2 alignments were constructed using the MAFFT version 7 (http://mafft.cbrc.jp/alignment/server/) [113] and Gblocks version 0.91b (http://www.phylogeny.fr/ version2_cgi/one_task.cgi?task_type=gblocks) software programs [114-116] to eliminate poorly aligned and highly divergent regions. Default parameters were used for both of these methods. The Tamura 3-parameter model (T92) [117] and $\mathrm{HKY}$ with evolutionary invariable (HKY+I) for Gblockstreated MAFFT ITS1 and ITS2 data, respectively, were used to infer evolutionary history inference using the ML method.

The Bayesian analysis was performed using MrBayes version 3.1.2 software [118, 119]. Two replicate analyses of 1 million generations each were performed for each dataset, with sampling every 10 generations. The hierarchical likelihood ratio test (hLRT) implemented in MrModeltest version 2.3 software [120] was used to identify the model of best fit (Hasegawa-Kishino-Yano with invariant sites and gamma distribution shape parameter $(\mathrm{HKY}+\mathrm{I}+\mathrm{G})$ [112] for ITS1 and the HKY+G model for ITS2). Trees from the first 53,000 and 118,000 generations were discarded as burn-in for ITS1 and ITS2, respectively. The Bayesian tree was estimated from the majority-rule consensus of the post-burn-in trees.

A reticulogram [121] was constructed using the TREX version 4.01a software [122] with the distance matrix computed using the Kimura 2-parameters model (ignoring missing bases); the weighted least-squares method was used for tree reconstruction [123], and addition of reticulation branches stopped when $K=1$ branches were added.

Network reconstruction was performed using Splits Tree 4 version 4.11 .3 software [65]. The neighbor-net network 
method and uncorrected $p$-distances were used to analyze and visualize reticulate relationships. All gaps were excluded for analysis. Network robustness was tested using 1,000 bootstrap replicates.

\section{Results and Discussion}

3.1. Characteristics and Analysis of an rDNA Sequence Dataset. In each species, the nucleotide sequences of the amplified rDNA region and five clones were not significantly different from each other. The frequency of variable nucleotides did not exceed the average rate of nucleotide substitutions caused by DNA polymerase errors, which is approximately one substitution per 1,000 nucleotides. The compared sequences contained both relatively evolutionarily conserved (fragments of $18 \mathrm{~S}$ and $28 \mathrm{~S}$ rDNA and the complete 5.8S rDNA) and evolutionary variable genomic regions (ITS1 and ITS2). For different taxa, the ITS1 and ITS2 sequences vary significantly among individuals at the inter- and intrapopulation levels; furthermore, these sequences can exhibit intragenomic variability $[25,41,53,54]$. Recently, a high level of intrapopulation polymorphism of the $28 \mathrm{~S}$ rDNA sequences was observed within Oithona spp. [22]. However, there are instances of strong evolutionary conservation of the $28 \mathrm{~S}$ and ITS sequences $[15,23,30,34]$. Notably, the M. leuckarti ITS2 sequence obtained in this study did not exhibit any nucleotide substitutions compared to the M. leuckarti ITS2 sequence described previously (GenBank accession number GQ848499) [42]. Therefore, the strong evolutionary conservation of ITS1 and ITS2 sequences is a characteristic feature of the copepod species analyzed in this study.

In this study, the applicability of different segments of rDNA containing the ITS1 and ITS2 regions, the 5.8S RNA gene, and fragments of the $18 \mathrm{~S}$ and $28 \mathrm{~S}$ rRNA genes was examined for reconstruction of the phylogenetic relationships among freshwater cyclopoid copepods. The 5.8S gene and the analyzed fragment of the $18 \mathrm{~S}$ gene were not considered for phylogenetic reconstruction due to their short length and strong evolutionary conservation: only a few nucleotide substitutions were detected by comparing these sequences with evolutionary distant species (data not shown).

For 15 specimens of Cyclopoida species (including the two marine species), the average length of the $28 \mathrm{~S}$ gene fragment sequenced was $1051 \mathrm{bp}$. We trimmed these sequences to 703 bp and compared them with the $28 \mathrm{~S}$ gene sequences of marine species available in GenBank. These 703 bp of $28 \mathrm{~S}$ rDNA sequences were aligned, and 342 variable sites were observed. Oncaea sp. (Oncaeidae family) was used as the out group.

The ITS1 sequence lengths varied from 267 to $388 \mathrm{bp}$ among the 13 Cyclopidae specimens. The ITS1 sequence alignments possessed 442 characters, and among them, 283 were variable. The ITS 2 sequence lengths varied from 188 to 262 bp among the 13 Cyclopidae specimens. ITS2 sequence alignment possessed 302 characters, and 190 were variable.

All alignment sets were examined for homogeneity of base frequencies and substitution saturation. The average base frequencies of the $28 \mathrm{~S}$ gene fragment $(A=20.52$,
TABLE 1: False test of substitution saturation.

\begin{tabular}{lccc}
\hline Alignment & Iss & Iss.c & Std. error \\
\hline 28S & 0.200 & 0.739 & 0.019 \\
ITS1 & 0.427 & 0.679 & 0.044 \\
ITS2 & 0.376 & 0.665 & 0.043 \\
\hline
\end{tabular}

Testing whether the observed Iss is significantly $(P<0.001$, two-tailed $t$ test) lower than the Iss.c for a symmetrical tree.

$C=25.33, G=32.75$, and $T=21.40 \%)$ differed from the ITS1 $(A=14.27, C=30.68, G=27.55$, and $T=27.50 \%)$ and ITS2 $(A=13.08, C=29.64, G=30.08$, and $T=$ $27.19 \%)$ regions. Gaps were excluded while estimating the average base frequencies of the ITS sequences. Using the chisquared test, no significant differences were observed in the base compositions of the 28S $\left(\chi^{2}=39.77, d f=54\right.$, and $P=0.93)$, ITS1 $\left(\chi^{2}=22.04, d f=36\right.$, and $\left.P=0.97\right)$, and ITS2 $\left(\chi^{2}=22.65, d f=36\right.$, and $\left.P=0.96\right)$ sequences among different taxa.

To analyze whether the divergence of 28S, ITS1, and ITS2 rDNA fragments among species was saturated, we performed a substitution saturation test and generated saturation plots. Using DAMBE, the substitution saturation test revealed an Iss value that was significantly $(P<0.001)$ lower than the Iss.c in all cases (Table 1). This result indicated the suitability of the data for phylogenetic analysis. The total numbers of transition and transversion substitutions were plotted individually against model-corrected maximum-likelihood pairwise distances for the 28S, ITS1, and ITS2 sequences (see Supplementary Figure 1 in Supplementary Material available online at http://dx.doi.org/10.1155/2014/926342). Using linear regression analysis on the 28S, ITS1, and ITS2 saturation graphs, the coefficients of determination $\left(R^{2}\right)$ were calculated for both classes of substitutions: for transitions, the $R^{2}$ values were $0.79,0.68$, and 0.74 for the $28 \mathrm{~S}$, ITS1, and ITS2 sequences, respectively; for transversions, the $R^{2}$ values were $0.95,0.93$, and 0.91 for the 28S, ITS1, and ITS2 sequences, respectively. The $R^{2}$ values indicated that no less than $70 \%$ of the total variation in pairwise transitions and transversions could be explained by the linear relationship between pairwise distances and the total number of transitions and transversions. All saturation plots showed significant linear correlations (Supplementary Figure 1). Therefore, both transitions and transversions steadily accumulated as the corrected pairwise divergence increased, indicating that saturation was not reached.

3.2. Distance Analyses and Phylogenetic Tree Reconstruction. Phylogenetic analysis of the cyclopoid copepods species based on rDNA showed that the $28 \mathrm{~S}$ rDNA sequences are informative for the phylogeny of both higher-level and closely related Copepoda species, whereas the ITS1 and ITS2 sequences are highly informative for reconstruction of the evolutionary history of closely related species. The ITS1 and ITS2 sequences are known to evolve more rapidly than the ribosomal RNA genes. Consistent with this observation, in 


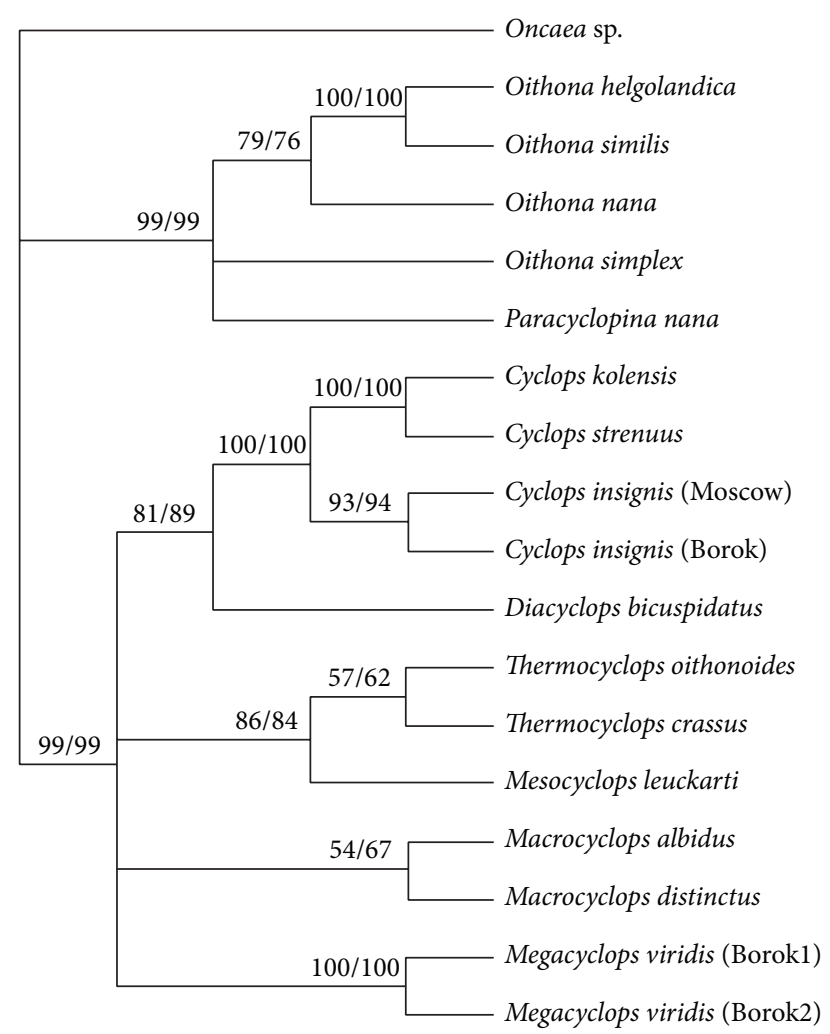

FIgURE 2: Phylogenetic relationships of Cyclopoida based on $\sim 700 \mathrm{bp}$ of the $28 \mathrm{~S}$ rRNA gene. The consensus cladogram inferred from the $28 \mathrm{~S}$ ribosomal DNA fragment sequence data of 16 Podoplea superorder species using maximum likelihood (ML) analysis under the $\mathrm{HKY}+\mathrm{G}$ model and minimum evolution (ME) analysis. The numbers above branches indicate bootstrap percentages. The values are listed for ML/ME.

this study, the pairwise ITS1/ITS2 $p$-distances were significantly higher thanthe $28 \mathrm{~S} p$-distances (compare Tables 2 and 3). These data are consistent with other studies showing considerable variation in ITS1 and ITS2 divergence levels among different groups of copepods [40, 42, 52, 124, 125]. In this study, fragments of $28 \mathrm{~S}$ rDNA sequences were used for the analysis of marine and freshwater cyclopoid copepods species, whereas ITS1 and ITS2 sequences were used exclusively for the analysis of freshwater cyclopoid copepods species.

The cladogram based on comparison of the $28 \mathrm{~S}$ rDNA sequences reflected the evolutionary history of the analyzed species (Figure 2). Oncaea sp. was used as the out group. Similar topologies and levels of support at most nodes were obtained for all 28S phylogenetic trees constructed using the ML and ME methods. The specimens belonging to the order Cyclopoida with high bootstrap support (ML/ME 99) formed two major clades on the tree (Figure 2). One clade combined the marine cyclopoid copepods species, whereas the freshwater species specimens formed the second clade. The $p$-distance between these two clades varied in the range of $0.171-0.245$ (Table 2). The $28 \mathrm{~S}$ phylogenetic tree revealed detailed relationships among the Oithona spp. with high bootstrap support (ML 79, 100 and ME 76, 100). However,

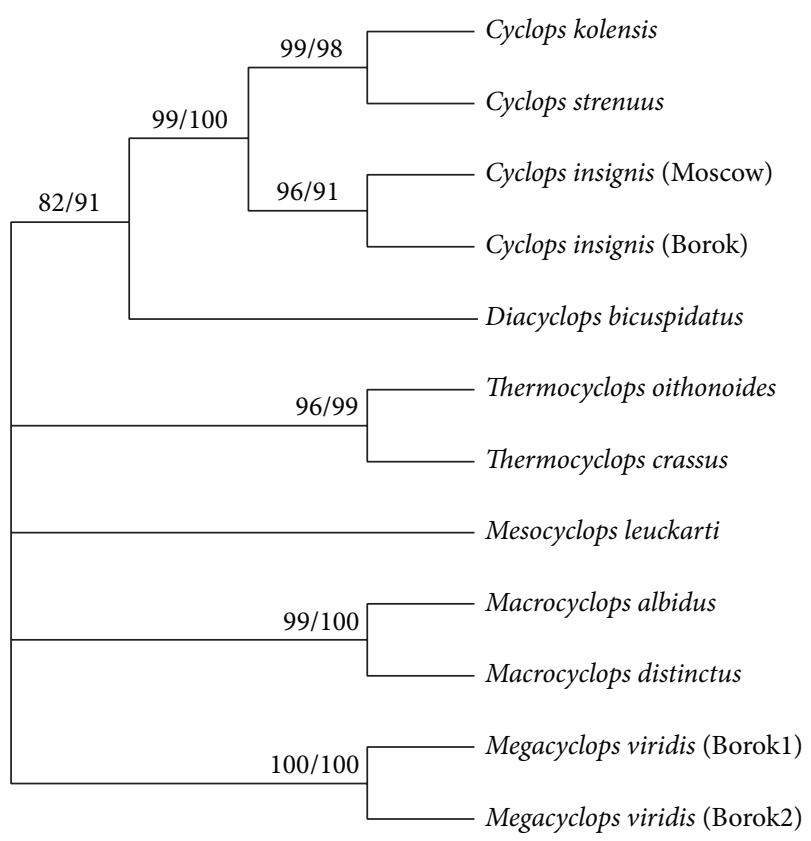

FIGURE 3: Phylogenetic relationships of Cyclopoida based on $\sim 500$ bp of concatenated ITS1/ITS2 rDNA sequences. The consensus cladogram inferred from the ITS1-ITS2 ribosomal DNA fragment sequence data of 10 species of the Cyclopidae family using maximum likelihood analysis under the $\mathrm{HKY}+\mathrm{G}$ model and minimum evolution (ME) analysis. The numbers above branches indicate bootstrap percentages. The values are listed for ML/ME.

P. nana (Cyclopettidae family) and Oithona spp. (Oithonidae family) were poorly resolved. Notably, this study is the second on the molecular phylogenetics of the Oithona spp; the previous study described the phylogenetic relationships between three Oithona spp.: O. similis, O. atlantica, and $O$. nana [22].

The cladogram based on the comparison of the concatenated ITS1/ITS2 sequences is shown in Figure 3. Notably, the $28 \mathrm{~S}$ and ITS1/ITS2 cladograms had several common features, reflecting the evolutionary history of the analyzed freshwater cyclopoid copepods species. Both cladograms revealed that $D$. bicuspidatus and specimens of the Cyclops genus with high bootstrap values $(>80)$ are separated from other studied freshwater copepods in a distinct clade. The $p$ distance between D. bicuspidatus and Cyclops spp. calculated based on ITS1/ITS2 analysis varied in the range of $0.232-$ 0.250 , whereas the $p$-distance between $D$. bicuspidatus and Thermocyclops spp. varied in the range of 0.298-0.333, and the $p$-distance between $D$. bicuspidatus and other analyzed freshwater species varied in the range of $0.310-0.405$. This result is consistent with a previous phylogenetic study based on $18 \mathrm{~S}$ rDNA sequence analysis [48]. Notably, the systematic position of this species, based solely on the analysis of morphological characteristics, remained unclear. Diacyclops bicuspidatus is considered to be evolutionarily closer to Thermocyclops spp. [8].

Another important conclusion from the analysis of $28 \mathrm{~S}$ and ITS1/ITS2 cladograms relates to the systematic position of C. strenuus. The Cyclops genera subclade was divided into 


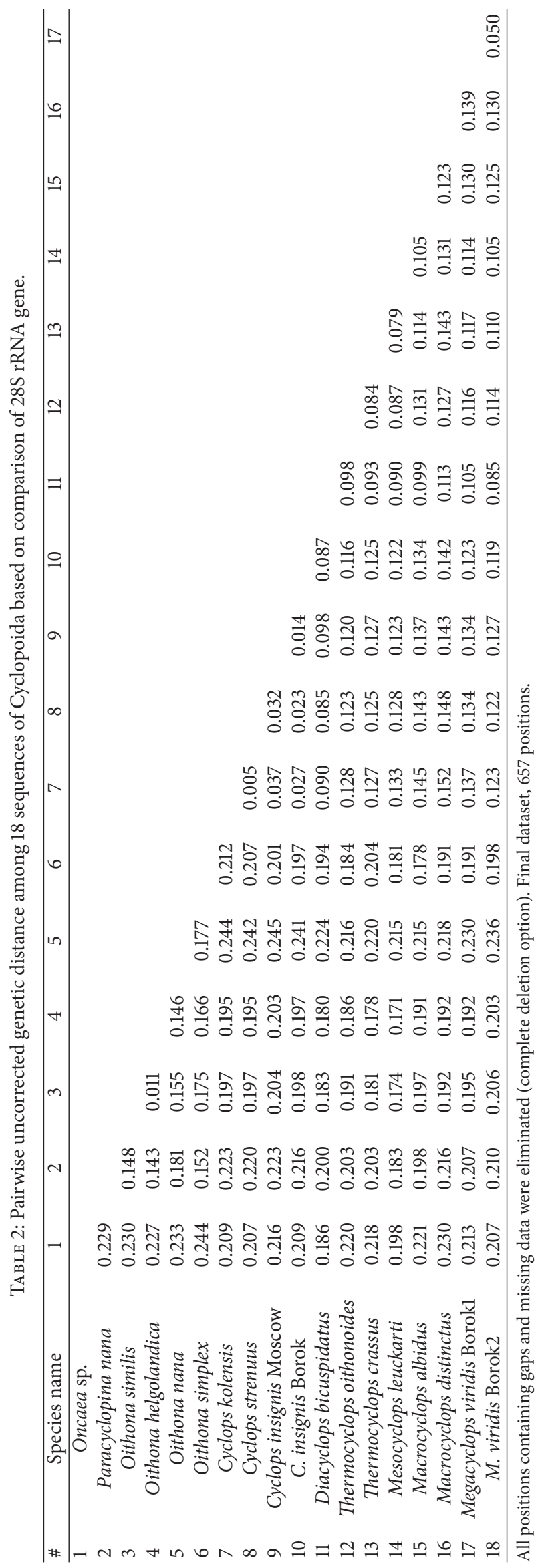




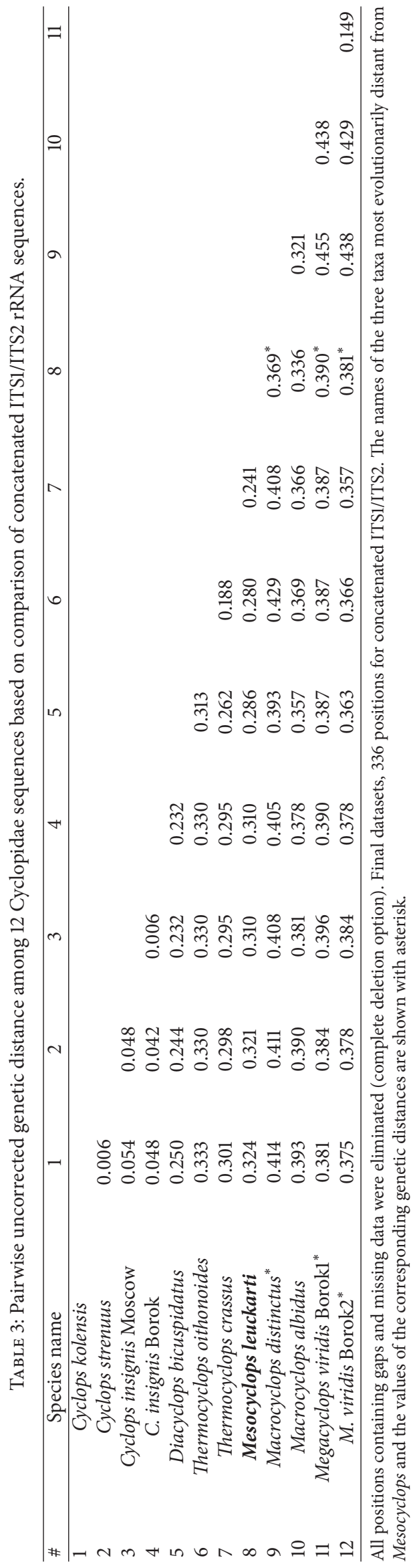




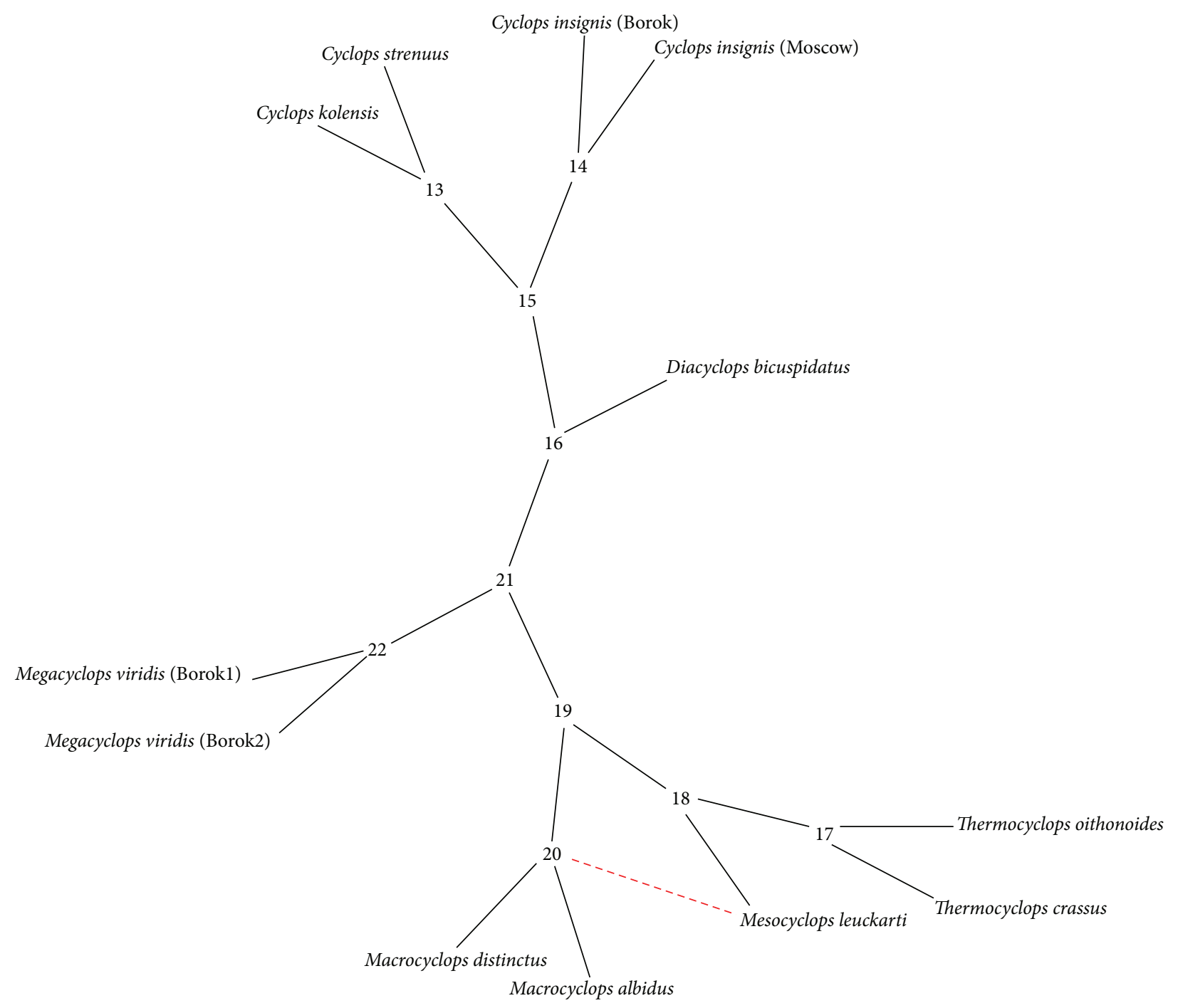

FIgURE 4: Reticulogram for concatenated ITS1/ITS2 sequences of 10 species of the Cyclopidae family. The red dashed line indicates the reticulation event connecting $M$. leuckarti to the Macrocyclops clade node. The number of internal vertices begins with $n+1$, where $n$ is the number of leaves. The order of internal vertices distribution corresponds to the increasing lengths of the 22 reticulogram edges.

the C. kolensis: C. strenuus subsubclade and the C. insignis subsubclade (Figures 2 and 3). The p-distance between C. strenuus and C. kolensis calculated based on ITS1/ITS2 analysis is 0.006 , whereas the $p$-distance between C. strenuus and $C$. insignis varied in the range of $0.042-0.054$. Therefore, C. strenuus is more closely related to C. kolensis than to $C$. insignis. Notably, the phylogenetic relationships between the studied Cyclops species could not be elucidated solely on the basis of morphological characteristics.

The only difference between the $28 \mathrm{~S}$ and ITS1/ITS2 cladograms within freshwater copepods was the position of M. leuckarti (Figures 2 and 3). The cladogram based on comparison of the $28 \mathrm{~S}$ rDNA sequences showed that the M. leuckarti and Thermocyclops cluster together to form a separate subclade (Figure 2). This result is consistent with the previous observation that the Mesocyclops and Thermocyclops genera are phylogenetically closely related, which was confirmed by the similarity of morphological characteristics and using molecular data [42]. ITS1/ITS2 analysis revealed that $M$. leuckarti is located separately from Thermocyclops and other clades (Figure 3). Using phylogenetic networks, we analyzed whether the $M$. leuckarti position in the ITS1/ITS2 cladogram was caused by different contributions of ITS1 and ITS2 sequences to the phylogenetic signal.

3.3. Phylogenetic Networks. A reticulogram-based phylogenetic network inference approach was used to verify the reticulate evolution of the studied copepods. Concatenated ITS1/ITS2 sequences of 10 species from the Cyclopidae family were used for reticulogram reconstruction. The reticulogram revealed a network with Mesocyclops and Thermocyclops clustered together and a reticulation (lateral branch) connecting M. leuckarti to the Macrocyclops clade node (Figure 4). Therefore, the reticulogram indicated the reticulation in Mesocyclops evolution. 


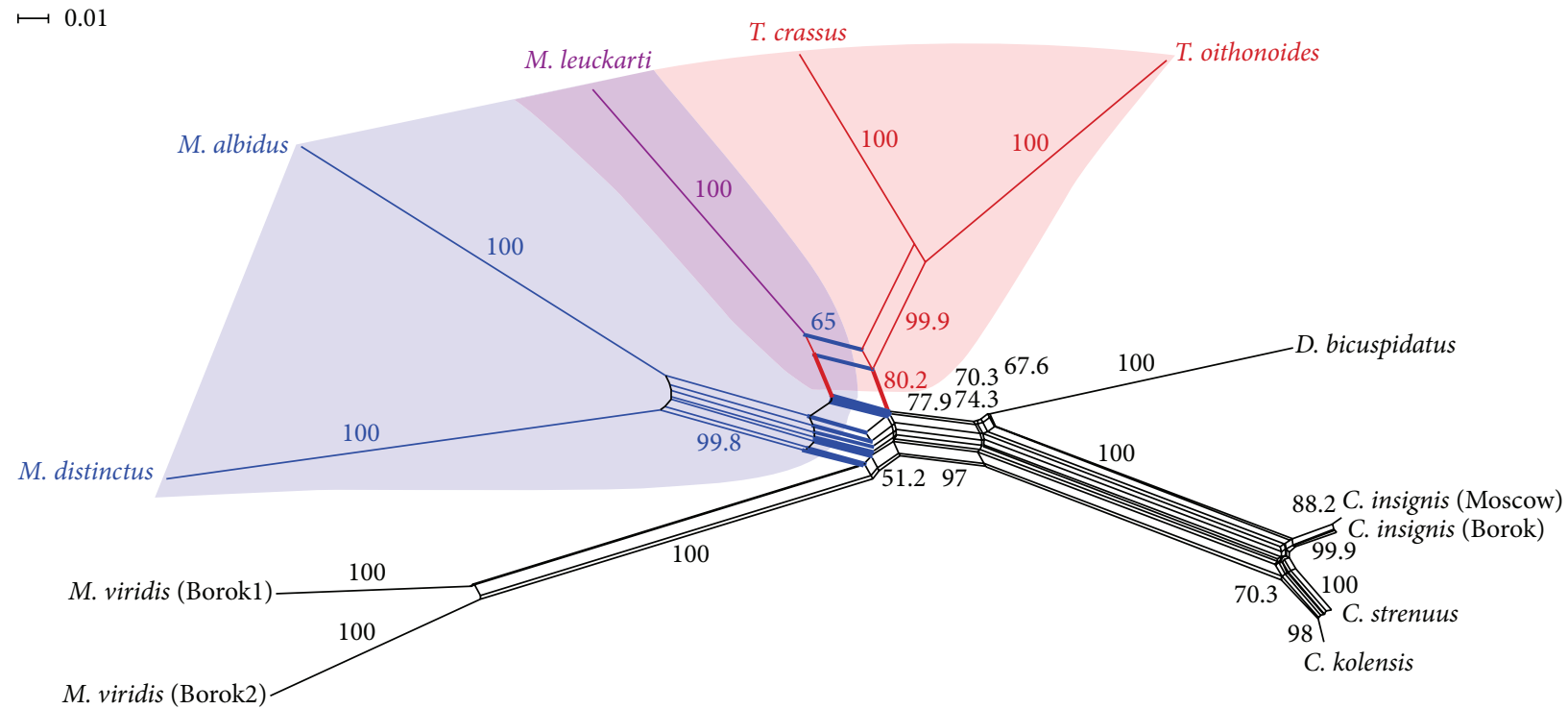

FIGURE 5: Split networks for concatenated ITS1/ITS2 sequences of 10 species of the Cyclopidae family. Split network based on concatenated ITS1/ITS2 sequences; the split separating M. leuckarti, T. oithonoides, and T. crassus is indicated in bold red; the split separating M. leuckarti, M. distinctus, and M. albidus is indicated in bold blue; purple indicates the M. leuckarti reticulate relationship with Thermocyclops and Macrocyclops. The values on the branches indicate bootstrap percentages.

A split network represents incompatible edges of trees as a band of parallel edges. Parallel edges split a network into two sets of nodes. Split-graph analysis of concatenated ITS1/ITS2 sequences of 10 species from the Cyclopidae family revealed a reticulate relationship between Mesocyclops, Thermocyclops, and Macrocyclops with high reliability (Figure 5). All principal splits were well supported. Two splits were observed in the ITS1/ITS2 split network. The first split (parallel edges highlighted with bold red) separated M. leuckarti, T. oithonoides, and $T$. crassus with $80.2 \%$ bootstrap support. The second split (parallel edges highlighted with bold blue) separated $M$. leuckarti, $M$. distinctus, and M. albidus with $65.0 \%$ bootstrap support.

In addition to the network data, we performed phylogenetic reconstruction based on independent ITS1 and ITS2 analyses using probabilistic and distance methods. Irrespective of the method used, the main difference between the topologies of the ITS1 and ITS2 phylogenetic trees was as follows: based on the ITS1 analysis, M. leuckarti is clustered with Thermocyclops, whereas the ITS2 analysis revealed that M. leuckarti clustered with Macrocyclops (Figures 6(a)-6(d)).

The impact of the chosen DNA sequence on the clustering of $M$. leuckarti might reflect the different evolutionary histories of ITS1 and ITS2, which indicates the potential hybrid origin of $M$. leuckarti. However, the values of bootstrap support for the clustering of Mesocyclops and Thermocyclops and of Mesocyclops and Macrocyclops depended on the method used for phylogenetic tree reconstruction and varied over a wide range (Figures 6(a)-6(d)).

Phylogenetic trees can be inconsistent due to the socalled long-branch attraction (LBA) phenomenon, which occurs when two nonadjacent taxa share many homoplastic character states along long branches and/or from uncorrected sequence alignments. Interpretation of the observed similarity depends on the method used for phylogenetic analysis, and this similarity can often be interpreted as homology. Model-based methods are most resistant to LBA, but these methods can exhibit LBA if their assumptions are seriously violated or if there are insufficient taxa in the analysis to accurately estimate the parameters of the evolutionary model [126]. Taxon sampling is a crucial factor for avoiding LBA in phylogenetic analysis [127]. The inclusion of additional taxa in phylogenetic analysis increases the accuracy of the inferred topology by dispersing homoplasty across the tree and reducing the effect of LBA. The LBA effect might also be revealed by exclusion of the long-branched taxon from the analysis [127].

To reduce the possible effects of LBA and correctness of the sequence alignment, we used the following approaches: (1) three taxa the most evolutionarily distant from $M$. leuckarti (M. distinctus, M. viridis Borok1, and M. viridis Borok2) were removed from the list of species used for ITS1 and ITS2 phylogenetic tree reconstruction (the taxa selection was based on the data presented in Table 3) and (2) ITS1 and ITS2 sequences were aligned using new multiple sequence alignment programs to eliminate poorly aligned and highly divergent regions (see Section 2). The final ITS1 and ITS2 alignments are shown in Supplementary Figures 2 (a) and 2(b), and the resulting phylogenetic trees are shown in Figures 6(e) and 6(f). Based on the ITS1 analysis, $M$. leuckarti clustered with Thermocyclops, whereas the ITS2 analysis revealed that $M$. leuckarti clustered with Macrocyclops (Figures 6(e) and 6(f)). Notably, the topology of the new phylogenetic trees had high bootstrap support: $84(\mathrm{ML}) / 77$ (ME) for ITS1 and 77 (ML)/72 (ME) for ITS2 (Figures 6(e) and 6(f)). 


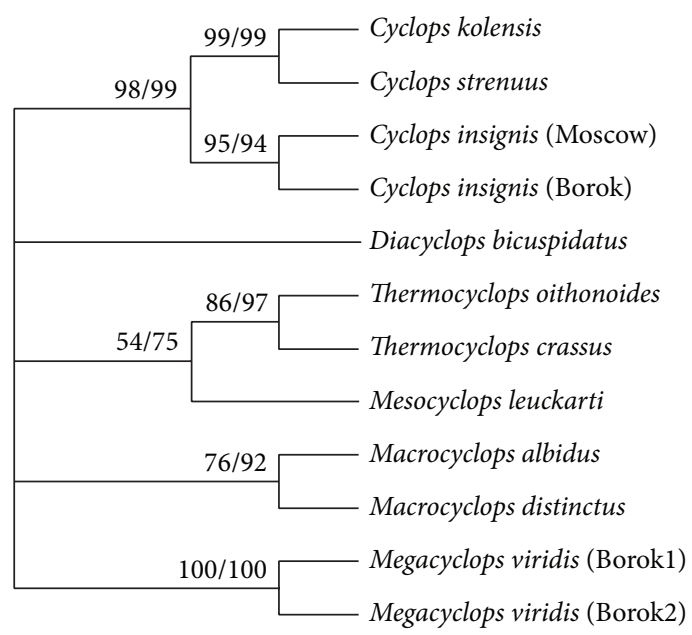

(a)

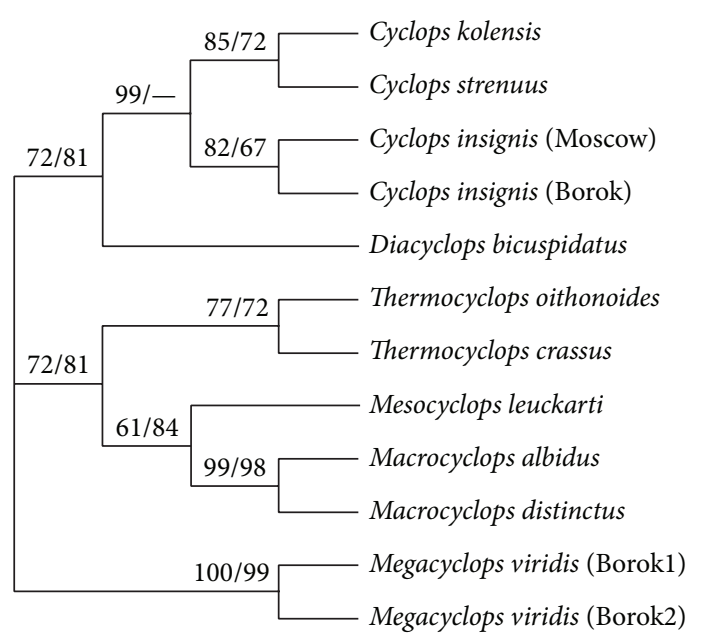

(c)

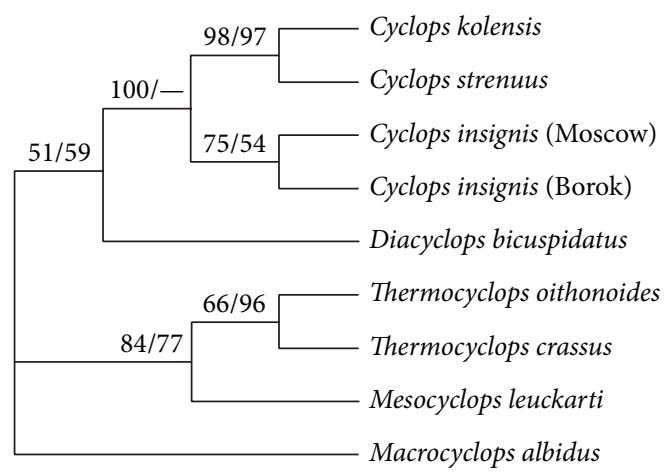

(e)

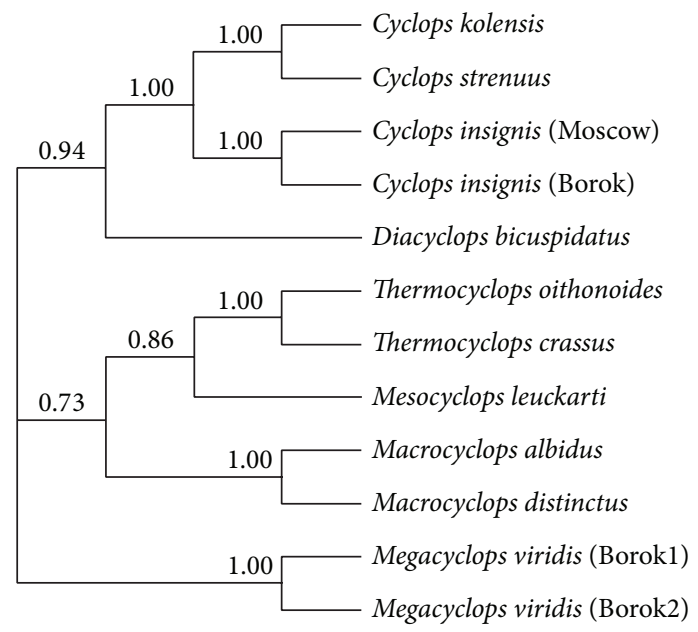

(b)

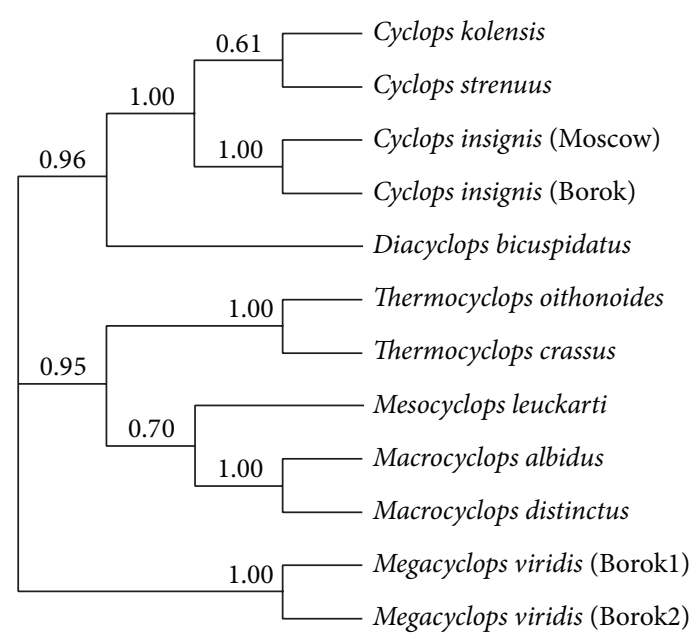

(d)

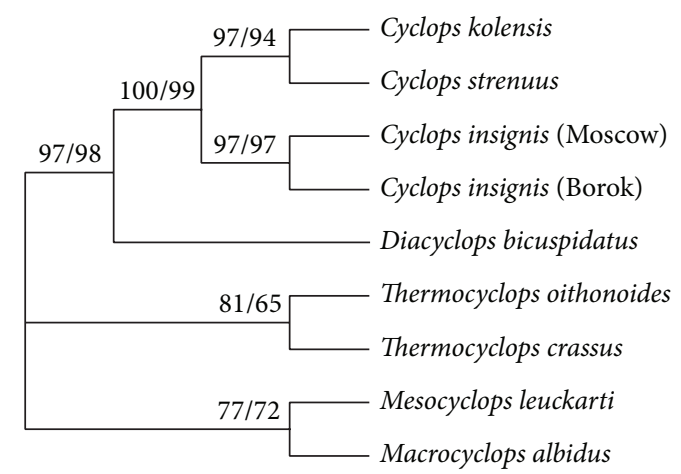

(f)

FIgURE 6: Phylogenetic relationships of Cyclopidae based on ITS1 and ITS2 sequences. The ITS1 consensus Clustal tree of ten Cyclopidae species constructed using (a) maximum likelihood and minimum evolution and (b) Bayesian inference. The ITS2 consensus Clustal tree of ten Cyclopidae species constructed using (c) maximum likelihood and minimum evolution and (d) Bayesian inference. The consensus Gblocks-treated MAFFT trees of eight Cyclopidae species constructed using maximum likelihood and minimum evolution: (e) ITS1, (f) ITS2. The numbers above the branches indicate bootstrap percentages and Bayesian posterior probabilities. The values are listed for ML/ME. Missing or weakly supported nodes $(<50 \%$ or 0.5$)$ are denoted by a “-”. 
We think that one of the most intriguing explanations for the observed differences in the clustering of M. leuckarti is the interspecific hybridization between extinct taxa (presumably closely related) that were ancestral to both Mesocyclops, Macrocyclops, and Thermocyclops. However, a rigorous proof of this hypothesis requires further analysis of a larger number of species. This will be the subject of our further research.

\section{Conclusion}

We evaluated the utility of a $2000 \mathrm{bp}$ fragment of rDNA (easily amplified by universal primers) for the phylogenetic reconstruction of the relationships of Copepoda species. Our data showed that the 28S rDNA and the ITS1 and ITS2 regions are highly informative for the phylogeny of both higher-level and closely related Copepoda species. Comparative analysis of the ITS1 and ITS2 nucleotide sequences among closely related Copepoda species revealed an unusual evolutionary history of these spacer sequences; therefore, the ITS1 and ITS2 regions might contain different phylogenetic signals.

\section{Conflict of Interests}

The authors declare that there is no conflict of interests regarding the publication of this paper.

\section{Acknowledgments}

The authors would like to thank Grace A. Wyngaard for criticisms and comments on earlier versions of this paper. This project was supported in part by a Russian Foundation for Basic Research Grant no. 12-04-32032-a to Maxim V. Zagoskin, Grants nos. 06-04-48474-a and 10-04-01376-a to Andrey K. Grishanin, and a Russian Academy of Sciences grant "Wild life: current status and development problems" (subprogram "Dynamics and Conservation of Gene Pools") to Dmitry V. Mukha.

\section{References}

[1] G. A. Boxshall and D. Defaye, "Global diversity of copepods (Crustacea: Copepoda) in freshwater," Hydrobiologia, vol. 595, no. 1, pp. 195-207, 2008.

[2] B. Dussart and D. Defaye, World Directory of Crustacea Copepoda of Inland Waters. II-Cyclopiformes, Backhuys, Leiden, The Netherlands, 2006.

[3] F. Kiefer, "Versuch eines Systems der Cyclopiden," Zoologischer Anzeiger, vol. 73, no. 11-12, pp. 302-308, 1927.

[4] R. Gurney, British Fresh-Water Copepoda. III. Cyclopoida, Ray Society, London, UK, 1933.

[5] V. M. Rylov, Cyclopoida presnykh vod. Freshwater Cyclopoida V.3, Leningrad, Moscow, Russia, 1948.

[6] H. C. Yeatman, "Free-living Copepoda. Cyclopoida," in Freshwater Biology, W. T. Edmondson, Ed., pp. 795-815, John Wiley \& Sons, New York, NY, USA, 1959.

[7] B. Dussart, Les Copépodes des Eaux Continentales de Europe Occidentals, Vol. 2. Cyclopoides et Biologie, N. Boubée, Paris, France, 1969.
[8] V. I. Monchenko, "Gnathostomata cyclopoida: cyclopidae," The Fauna of Ukraina Naukova Dumka, Kiev, USSR, vol. 27, no. 3, pp. 1-452, 1974, http://scholar.google.ru/citations?view_ op=view_citation\&hl=ru\&user=b97TEWUAAAAJ\&citation for_view=b97TEWUAAAAJ:hqOjcs7Dif8C.

[9] A. Bucklin, B. W. Frost, and T. D. Kocher, "DNA sequence variation of the mitochondrial 16S rRNA in Calanus (Copepoda: Calanoida): intraspecific and interspecific patterns," Molecular Marine Biology and Biotechnology, vol. 1, no. 6, pp. 397-407, 1992.

[10] A. Bucklin, T. C. LaJeunesse, E. Curry, J. Wallinga, and K. Garrison, "Molecular diversity of the copepod, Nannocalanus minor: genetic evidence of species and population structure in the North Atlantic Ocean," Journal of Marine Research, vol. 54, no. 2, pp. 285-310, 1996.

[11] R. S. Burton, "Intraspecific phylogeography across the point conception biogeographic boundary," Evolution, vol. 52, no. 3, pp. 734-745, 1998.

[12] C. C. Caudill and A. Bucklin, "Molecular phylogeography and evolutionary history of the estuarine copepod, Acartia tonsa, on the Northwest Atlantic coast," Hydrobiologia, vol. 511, pp. 91-102, 2004.

[13] S. Edmands, "Phylogeography of the intertidal copepod Tigriopus californicus reveals substantially reduced population differentiation at northern latitudes," Molecular Ecology, vol. 10, no. 7, pp. 1743-1750, 2001.

[14] S. Eyun, Y. Lee, H. Suh, S. Kim, and Y. S. Ho, "Genetic identification and molecular phylogeny of Pseudodiaptomus species (Calanoida, Pseudodiaptomidae) in Korean waters," Zoological Science, vol. 24, no. 3, pp. 265-271, 2007.

[15] E. Goetze, "Population differentiation in the open sea: insights from the pelagic copepod pleuromamma xiphias," Integrative and Comparative Biology, vol. 51, no. 4, pp. 580-597, 2011.

[16] S. Laakmann and S. Holst, "Emphasizing the diversity of North Sea hydromedusae by combined morphological and molecular methods," Journal of Plankton Research, vol. 36, no. 1, pp. 64-76, 2014.

[17] P. K. Lindeque, R. P. Harris, M. B. Jones, and G. R. Smerdon, "Distribution of Calanus spp. as determined using a genetic identification system," Scientia Marina, vol. 68, supplement 1, pp. 121-128, 2007.

[18] W. Minxiao, S. Song, L. Chaolun, and S. Xin, "Distinctive mitochondrial genome of Calanoid copepod Calanus sinicus with multiple large non-coding regions and reshuffled gene order: useful molecular markers for phylogenetic and population studies," BMC Genomics, vol. 12, no. 1, article 73, 2011.

[19] P. D. Rawson and R. S. Burton, "Molecular evolution at the cytochrome oxidase subunit 2 gene among divergent populations of the intertidal copepod, Tigriopus californicus," Journal of Molecular Evolution, vol. 62, no. 6, pp. 753-764, 2006.

[20] H. Y. Soh, E. Ok Park, B. A. Venmathi Maran, and S. Yong Moon, "A new species of Acartia subgenus Euacartia (Copepoda: Calanoida: Acartiidae) from Korean estuaries based on morphological and molecular evidence," Journal of Crustacean Biology, vol. 33, no. 5, pp. 718-729, 2013.

[21] C. S. Willett and J. T. Ladner, "Investigations of fine-scale phylogeography in Tigriopus californicus reveal historical patterns of population divergence," BMC Evolutionary Biology, vol. 9, no. 1, article 139, 2009.

[22] G. D. Cepeda, L. Blanco-Bercial, A. Bucklin, C. M. Berón, and M. D. Viñas, "Molecular systematic of three species of Oithona 
(Copepoda, Cyclopoida) from the Atlantic ocean: comparative analysis using $28 \mathrm{~S}$ rDNA," PLoS ONE, vol. 7, no. 4, Article ID e35861, 2012.

[23] J. Hirai, S. Shimode, and A. Tsuda, "Evaluation of ITS2-28S as a molecular marker for identification of calanoid copepods in the subtropical western North Pacific," Journal of Plankton Research, vol. 35, no. 3, pp. 644-656, 2013.

[24] J. Kim and W. Kim, "Molecular phylogeny of poecilostome copepods based on the $18 \mathrm{~S}$ rDNA sequences," Korean Journal of Biological Sciences, vol. 4, no. 3, pp. 257-261, 2000.

[25] A. P. Shinn, B. A. Banks, N. Tange et al., "Utility of $18 \mathrm{~S}$ rDNA and ITS sequences as population markers for Lepeophtheirus salmonis (Copepoda: Caligidae) parasitising Atlantic salmon (Salmo salar) in Scotland," Contributions to Zoology, vol. 69, no. 1-2, pp. 89-98, 2000.

[26] S. J. Adamowicz, S. Menu-Marque, S. A. Halse et al., "The evolutionary diversification of the Centropagidae (Crustacea, Calanoida): a history of habitat shifts," Molecular Phylogenetics and Evolution, vol. 55, no. 2, pp. 418-430, 2010.

[27] L. Blanco-Bercial, J. Bradford-Grieve, and A. Bucklin, "Molecular phylogeny of the Calanoida (Crustacea: Copepoda)," Molecular Phylogenetics and Evolution, vol. 59, no. 1, pp. 103-113, 2011.

[28] E. Braga, R. Zardoya, A. Meyer, and J. Yen, "Mitochondrial and nuclear rRNA based copepod phylogeny with emphasis on the Euchaetidae (Calanoida)," Marine Biology, vol. 133, no. 1, pp. 7990, 1999.

[29] A. Bucklin, B. W. Frost, J. Bradford-Grieve, L. D. Allen, and N. J. Copley, "Molecular systematic and phylogenetic assessment of 34 calanoid copepod species of the Calanidae and Clausocalanidae," Marine Biology, vol. 142, no. 2, pp. 333-343, 2003.

[30] A. Bucklin and B. W. Frost, "Morphological and molecular Phylogenetic analysis of evolutionary lineages within Clausocalanus (Copepoda: Calanoida)," Journal of Crustacean Biology, vol. 29, no. 1, pp. 111-120, 2009.

[31] A. Cornils and L. Blanco-Bercial, "Phylogeny of the paracalanidae giesbrecht, 1888 (Crustacea: Copepoda: Calanoida)," Molecular Phylogenetics and Evolution, vol. 69, no. 3, pp. 861872, 2013.

[32] S. M. Dippenaar, "Estimated molecular phylogenetic relationships of six siphonostomatoid families (Copepoda) symbiotic on elasmobranchs," Crustaceana, vol. 82, no. 12, pp. 1547-1567, 2009.

[33] D. F. Figueroa, "Phylogenetic analysis of Ridgewayia (Copepoda: Calanoida) from the Galapagos and of a new species from the Florida keys with a reevaluation of the phylogeny of Calanoida," Journal of Crustacean Biology, vol. 31, no. 1, pp. 153165, 2011.

[34] E. Goetze, "Cryptic speciation on the high seas; global phylogenetics of the copepod family Eucalanidae," Proceedings of the Royal Society B: Biological Sciences, vol. 270, no. 1531, pp. 23212331, 2003.

[35] S. Laakmann, G. Gerdts, R. Erler, T. Knebelsberger, P. Martínez Arbizu, and M. J. Raupach, "Comparison of molecular species identification for North Sea calanoid copepods (Crustacea) using proteome fingerprints and DNA sequences," Molecular Ecology Resources, vol. 13, no. 5, pp. 862-876, 2013.

[36] R. J. Machida, M. U. Miya, M. Nishida, and S. Nishida, "Molecular phylogeny and evolution of the pelagic copepod genus Neocalanus (Crustacea: Copepoda)," Marine Biology, vol. 148, no. 5, pp. 1071-1079, 2006.

[37] M. Taniguchi, "Molecular phylogeny of Neocalanus copepods in the subarctic Pacific Ocean, with notes on non-geographical genetic variations for Neocalanus cristatus," Journal of Plankton Research, vol. 26, no. 10, pp. 1249-1255, 2004.

[38] C. E. Lee, "Global phylogeography of a cryptic copepod species complex and reproductive isolation between genetically proximate 'populations,' Evolution, vol. 54, no. 6, pp. 2014-2027, 2000.

[39] S. J. Adamowicz, S. Menu-Marque, P. D. N. Hebert, and A. Purvis, "Molecular systematics and patterns of morphological evolution in the Centropagidae (Copepoda: Calanoida) of Argentina," Biological Journal of the Linnean Society, vol. 90, no. 2, pp. 279-292, 2007.

[40] E. Goetze, "Global population genetic structure and biogeography of the oceanic copepods Eucalanus hyalinus and E. spinifer," Evolution, vol. 59, no. 11, pp. 2378-2398, 2005.

[41] R. J. Machida and A. Tsuda, "Dissimilarity of species and forms of planktonic Neocalanus copepods using mitochondrial COI, $12 \mathrm{~S}$, nuclear ITS, and $28 \mathrm{~S}$ gene sequences," PLoS ONE, vol. 5, no. 4, Article ID e10278, 2010.

[42] G. A. Wyngaard, M. Hołyńska, and J. A. Schulte, "Phylogeny of the freshwater copepod Mesocyclops (Crustacea: Cyclopidae) based on combined molecular and morphological data, with notes on biogeography," Molecular Phylogenetics and Evolution, vol. 55, no. 3, pp. 753-764, 2010.

[43] V. Alekseev, H. J. Dumont, J. Pensaert, D. Baribwegure, and J. R. Vanfleteren, "A redescription of Eucyclops serrulatus (Fischer, 1851) (Crustacea: Copepoda: Cyclopoida) and some related taxa, with a phylogeny of the E. serrulatus-group," Zoologica Scripta, vol. 35, no. 2, pp. 123-147, 2006.

[44] M. R. Miracle, V. Alekseev, V. Monchenko, V. Sentandreu, and E. Vicente, "Molecular-genetic-based contribution to the taxonomy of the Acanthocyclops robustus group," Journal of Natural History, vol. 47, no. 5-12, pp. 863-888, 2013.

[45] M. Bláha, M. Hulák, J. Slouková, and J. Těšitel, "Molecular and morphological patterns across Acanthocyclops vernalis-robustus species complex (Copepoda, Cyclopoida)," Zoologica Scripta, vol. 39, no. 3, pp. 259-268, 2010.

[46] T. Karanovic and M. Krajicek, "When anthropogenic translocation meets cryptic speciation globalized bouillon originates; molecular variability of the cosmopolitan freshwater cyclopoid Macrocyclops albidus (Crustacea: Copepoda)," Annales de Limnologie, vol. 48, no. 1, pp. 63-80, 2012.

[47] T. Karanovic and M. Krajicek, "First molecular data on the Western Australian Diacyclops (Copepoda, Cyclopoida) confirm morpho-species but question size differentiation and monophyly of the Alticola-group," Crustaceana, vol. 85, no. 1213, pp. 1549-1569, 2012.

[48] T. Y. Mayor, N. G. Sheveleva, L. V. Sukhanova, O. A. Timoshkin, and S. V. Kiril'chik, "Molecular-phylogenetic analysis of cyclopoids (Copepoda: Cyclopoida) from Lake Baikal and its water catchment basin," Russian Journal of Genetics, vol. 46, no. 11, pp. 1373-1380, 2010.

[49] T. Karanovic and S. J. B. Cooper, "Molecular and morphological evidence for short range endemism in the Kinnecaris solitaria complex (Copepoda: Parastenocarididae), with descriptions of seven new species," Zootaxa, no. 3026, pp. 1-64, 2011.

[50] F. Marrone, S. L. Brutto, and M. Arculeo, "Molecular evidence for the presence of cryptic evolutionary lineages in the freshwater copepod genus Hemidiaptomus G.O. Sars, 1903 (Calanoida, Diaptomidae)," Hydrobiologia, vol. 644, no. 1, pp. 115-125, 2010.

[51] R. Scheihing, L. Cardenas, R. F. Nespolo et al., "Morphological and molecular analysis of centropagids from the high Andean 
plateau (Copepoda: Calanoidea)," Hydrobiologia, vol. 637, no. 1, pp. 45-52, 2010.

[52] R. A. Thum and R. G. Harrison, "Deep genetic divergences among morphologically similar and parapatric Skistodiaptomus (Copepoda: Calanoida: Diaptomidae) challenge the hypothesis of Pleistocene speciation," Biological Journal of the Linnean Society, vol. 96, no. 1, pp. 150-165, 2009.

[53] H. Y. Soh, S. W. Kwon, W. Lee, and Y. H. Yoon, "A new Pseudodiaptomus (Copepoda, Calanoida) from Korea supported by molecular data," Zootaxa, no. 3368, pp. 229-244, 2012.

[54] M. A. Marszalek, S. Dayanandan, and E. J. Maly, "Phylogeny of the genus Hesperodiaptomus (Copepoda) based on nucleotide sequence data of the nuclear ribosomal gene," Hydrobiologia, vol. 624, no. 1, pp. 61-69, 2009.

[55] R. A. Thum, "Using $18 \mathrm{~S}$ rDNA to resolve diaptomid copepod (Copepoda: Calanoida: Diaptomidae) phylogeny: an example with the North American genera," Hydrobiologia, vol. 519, no. 1-3, pp. 135-141, 2004.

[56] R. Huys, J. Llewellyn-Hughes, P. D. Olson, and K. Nagasawa, "Small subunit rDNA and Bayesian inference reveal Pectenophilus ornatus (Copepoda incertae sedis) as highly transformed Mytilicolidae, and support assignment of Chondracanthidae and Xarifiidae to Lichomolgoidea (Cyclopoida)," Biological Journal of the Linnean Society, vol. 87, no. 3, pp. 403425, 2006.

[57] R. Huys, J. Llewellyn-Hughes, S. Conroy-Dalton, P. D. Olson, J. N. Spinks, and D. A. Johnston, "Extraordinary host switching in siphonostomatoid copepods and the demise of the Monstrilloida: integrating molecular data, ontogeny and antennulary morphology," Molecular Phylogenetics and Evolution, vol. 43, no. 2, pp. 368-378, 2007.

[58] J. Ki, K. Lee, H. G. Park, S. Chullasorn, H. Dahms, and J. Lee, "Phylogeography of the copepod Tigriopus japonicus along the Northwest Pacific rim," Journal of Plankton Research, vol. 31, no. 2, pp. 209-221, 2009.

[59] P. D. N. Hebert, A. Cywinska, S. L. Ball, and J. R. DeWaard, "Biological identifications through DNA barcodes," Proceedings of the Royal Society B, vol. 270, no. 1512, pp. 313-321, 2003.

[60] R. J. Machida, M. U. Miya, M. Nishida, and S. Nishida, "Complete mitochondrial DNA sequence of Tigriopus japonicus (Crustacea: Copepoda)," Marine Biotechnology, vol. 4, no. 4, pp. 406-417, 2002.

[61] R. S. Burton, R. J. Byrne, and P. D. Rawson, "Three divergent mitochondrial genomes from California populations of the copepod Tigriopus californicus," Gene, vol. 403, no. 1-2, pp. 5359, 2007.

[62] S. A. Gerbi, "Evolution of ribosomal DNA," in Molecular Evolutionary Genetics, pp. 419-517, Plenum, New York, NY, USA, 1985.

[63] U. W. Hwang and W. Kim, "General properties and phylogenetic utilities of nuclear ribosomal DNA and mitochondrial DNA commonly used in molecular systematics.," Korean Journal of Parasitology, vol. 37, no. 4, pp. 215-228, 1999.

[64] D. M. Hillis and M. T. Dixon, "Ribosomal DNA: molecular evolution and phylogenetic inference," Quarterly Review of Biology, vol. 66, no. 4, pp. 411-453, 1991.

[65] D. H. Huson and D. Bryant, "Application of phylogenetic networks in evolutionary studies," Molecular Biology and Evolution, vol. 23, no. 2, pp. 254-267, 2006.

[66] D. M. Hillis, C. Moritz, and B. K. Mable, Eds., Molecular Systematics, Sinauer Associates, Sunderland, Mass, USA, 1996.
[67] E. V. Koonin, The Logic of Chance: The Nature and Origin of Biological Evolution, Pearson Education, FT Press, 2012.

[68] T. Sang, D. J. Crawford, and T. F. Stuessy, "Documentation of reticulate evolution in peonies (Paeonia) using internal transcribed spacer sequences of nuclear ribosomal DNA: implications for biogeography and concerted evolution," Proceedings of the National Academy of Sciences of the United States of America, vol. 92, no. 15, pp. 6813-6817, 1995.

[69] S. Giessler and C. C. Englbrecht, "Dynamic reticulate evolution in a Daphnia multispecies complex," Journal of Experimental Zoology A, Ecological Genetics and Physiology, vol. 311, no. 7, pp. 530-548, 2009.

[70] H. Kauserud and T. Schumacher, "Ribosomal DNA variation, recombination and inheritance in the basidiomycete Trichaptum abietinum: implications for reticulate evolution," Heredity, vol. 91, no. 2, pp. 163-172, 2003.

[71] P. M. W. Wyatt, C. S. Pitts, and R. K. Butlin, "A molecular approach to detect hybridization between bream Abramis brama, roach Rutlius rutilus and rudd Scardinius erythrophthalmus," Journal of Fish Biology, vol. 69, pp. 52-71, 2006.

[72] J. Fuertes Aguilar and G. Nieto Feliner, "Additive polymorphisms and reticulation in an ITS phylogeny of thrifts (Armeria, Plumbaginaceae)," Molecular Phylogenetics and Evolution, vol. 28, no. 3, pp. 430-447, 2003.

[73] H. Yamaji, T. Fukuda, J. Yokoyama et al., "Reticulate evolution and phylogeography in Asarumsect. Asiasarum (Aristolochiaceae) documented in internal transcribed spacer sequences (ITS) of nuclear ribosomal DNA," Molecular Phylogenetics and Evolution, vol. 44, no. 2, pp. 863-884, 2007.

[74] M. A. Hershkovitz, C. C. Hernández-Pellicer, and M. T. K. Arroyo, "Ribosomal DNA evidence for the diversification of Tropaeolum sect. Chilensia (Tropaeolaceae)," Plant Systematics and Evolution, vol. 260, no. 1, pp. 1-24, 2006.

[75] A. Hugall, J. Stanton, and C. Moritz, "Reticulate evolution and the origins of ribosomal internal transcribed spacer diversity in apomictic Meloidogyne," Molecular Biology and Evolution, vol. 16, no. 2, pp. 157-164, 1999.

[76] J. F. Wendel, A. Schnabel, and T. Seelanan, "Bidirectional interlocus concerted evolution following allopolyploid speciation in cotton (Gossypium)," Proceedings of the National Academy of Sciences of the United States of America, vol. 92, no. 1, pp. 280284, 1995.

[77] K. O’Donnell and E. Cigelnik, “Two divergent intragenomic rDNA ITS2 types within a monophyletic lineage of the fungus Fusarium are nonorthologous," Molecular Phylogenetics and Evolution, vol. 7, no. 1, pp. 103-116, 1997.

[78] K. O’Donnell, E. Cigelnik, and H. I. Nirenberg, "Molecular systematics and phylogeography of the Gibberella fujikuroi species complex," Mycologia, vol. 90, no. 3, pp. 465-493, 1998.

[79] C. M. Brasier, D. E. L. Cooke, and J. M. Duncan, "Origin of a new Phytophthora pathogen through interspecific hybridization," Proceedings of the National Academy of Sciences of the United States of America, vol. 96, no. 10, pp. 5878-5883, 1999.

[80] K. W. Hughes and R. H. Petersen, "Apparent recombination or gene conversion in the ribosomal ITS region of a Flammulina (Fungi, Agaricales) hybrid," Molecular Biology and Evolution, vol. 18, no. 1, pp. 94-96, 2001.

[81] G. Newcombe, B. Stirling, S. McDonald, and H. D. Bradshaw Jr., "Melampsora $\times$ columbiana, a natural hybrid of M. medusae and M. occidentalis," Mycological Research, vol. 104, no. 3, pp. 261-274, 2000. 
[82] K. H. Chu, C. P. Li, and H. Y. Ho, "The first internal transcribed spacer (ITS-1) of ribosomal DNA as a molecular marker for phylogenetic and population analyses in crustacea," Marine Biotechnology, vol. 3, no. 4, pp. 355-361, 2001.

[83] L. H. Rieseberg, "Hybrid origins of plant species," Annual Review of Ecology and Systematics, vol. 28, no. 1, pp. 359-389, 1997.

[84] R. Cui, M. Schumer, K. Kruesi, R. Walter, P. Andolfatto, and G. G. Rosenthal, "Phylogenomics reveals extensive reticulate evolution in Xiphophorus fishes," Evolution, vol. 67, no. 8, pp. 2166-2179, 2013.

[85] L. Bullini, "Origin and evolution of animal hybrid species," Trends in Ecology and Evolution, vol. 9, no. 11, pp. 422-426, 1994.

[86] T. E. Dowling and C. L. Secor, "The role of hybridization and introgression in the diversification of animals," Annual Review of Ecology and Systematics, vol. 28, pp. 593-619, 1997.

[87] J. Mallet, "Hybridization as an invasion of the genome," Trends in Ecology and Evolution, vol. 20, no. 5, pp. 229-237, 2005.

[88] U. Arnason, R. Spilliaert, A. Pálsdóttir, and A. Arnason, "Molecular identification of hybrids between the two largest whale species, the blue whale (Balaenoptera musculus) and the fin whale (B. physalus)," Hereditas, vol. 115, no. 2, pp. 183-189, 1991.

[89] A. V. Z. Brower, "Introgression of wing pattern alleles and speciation via homoploid hybridization in Heliconius butterflies: a review of evidence from the genome.", Proceedings Biological Sciences, vol. 280, no. 1752, Article ID 20122302, 2013.

[90] H. L. Carson, K. Y. Kaneshiro, and F. C. Val, "Natural hybridization between the sympatric Hawaiian species Drosophila silvestris and Drosophila heteroneura," Evolution, vol. 43, no. 1, pp. 190-203, 1989.

[91] S. Gießler and C. C. Englbrecht, "Dynamic reticulate evolution in a Daphnia multispecies complex," Journal of Experimental Zoology A: Ecological Genetics and Physiology, vol. 311, no. 7, pp. 531-549, 2009.

[92] S. Gießler, E. Mader, and K. Schwenk, "Morphological evolution and genetic differentiation in Daphnia species complexes," Journal of Evolutionary Biology, vol. 12, no. 4, pp. 710-723, 1999.

[93] D. J. Taylor, P. D. N. Hebert, and J. K. Colbourne, "Phylogenetics and evolution of the Daphnia longispina group (Crustacea) based on $12 \mathrm{~S}$ rDNA sequence and allozyme variation," Molecular Phylogenetics and Evolution, vol. 5, no. 3, pp. 495-510, 1996.

[94] R. Vergilino, S. Markova, M. Ventura, M. Manca, and F. Dufresne, "Reticulate evolution of the Daphnia pulex complex as revealed by nuclear markers," Molecular Ecology, vol. 20, no. 6, pp. 1191-1207, 2011.

[95] D. V. Mukha and A. P. Sidorenko, "Detection and analysis of Tetrahymena pyriformis 26S ribosomal DNA domain sequences, differing in degree of evolutionary conservation," Molekulyarnaya Biologiya, vol. 29, no. 3, pp. 529-537, 1995.

[96] D. V. Mukha and A. P. Sidorenko, "Identification of highly conservative domains within the $17 \mathrm{~s}$ ribosomal dna sequence from Tetrahymena pyriformis," Genetika, vol. 32, no. 11, pp. 1494-1497, 1996.

[97] D. V. Mukha, A. P. Sidorenko, I. V. Lazebnaya, B. M. Wiegmann, and C. Schal, "Analysis of intraspecies polymorphism in the ribosomal DNA cluster of the cockroach Blattella germanica," Insect Molecular Biology, vol. 9, no. 2, pp. 217-222, 2000.

[98] D. Mukha, B. M. Wiegmann, and C. Schal, "Evolution and phylogenetic information content of the ribosomal DNA repeat unit in the Blattodea (Insecta)," Insect Biochemistry and Molecular Biology, vol. 32, no. 9, pp. 951-960, 2002.
[99] F. Sanger, S. Nicklen, and A. R. Coulson, "DNA sequencing with chain-terminating inhibitors," Proceedings of the National Academy of Sciences of the United States of America, vol. 74, no. 12, pp. 5463-5467, 1977.

[100] M. A. Larkin, G. Blackshields, N. P. Brown et al., "Clustal W and Clustal X version 2.0,” Bioinformatics, vol. 23, no. 21, pp. 29472948, 2007.

[101] M. Goujon, H. McWilliam, W. Li et al., "A new bioinformatics analysis tools framework at EMBL-EBI," Nucleic Acids Research, vol. 38, no. 2, Article ID gkq313, pp. W695-W699, 2010.

[102] K. Tamura, D. Peterson, N. Peterson, G. Stecher, M. Nei, and S. Kumar, "MEGA5: molecular evolutionary genetics analysis using maximum likelihood, evolutionary distance, and maximum parsimony methods," Molecular Biology and Evolution, vol. 28, no. 10, pp. 2731-2739, 2011.

[103] X. Xia and Z. Xie, "DAMBE: software package for data analysis in molecular biology and evolution," Journal of Heredity, vol. 92, no. 4, pp. 371-373, 2001.

[104] X. Xia, Data Analysis in Molecular Biology and Evolution, Kluwer Academic Publishers, Boston, Mass, USA, 2000.

[105] X. Xia, Z. Xie, M. Salemi, L. Chen, and Y. Wang, "An index of substitution saturation and its application," Molecular Phylogenetics and Evolution, vol. 26, no. 1, pp. 1-7, 2003.

[106] P. Lemey, M. Salemi, and A.-M. Vandamme, Eds., The Phylogenetic Handbook: A Practical Approach to Phylogenetic Analysis and Hypothesis Testing, Cambridge University Press, Cambridge, UK, 2009.

[107] W. M. Fitch, "Toward defining the course of evolution: minimum change for a specific tree topology," Systematic Biology, vol. 20, no. 4, pp. 406-416, 1971.

[108] J. Felsenstein, "Evolutionary trees from DNA sequences: a maximum likelihood approach," Journal of Molecular Evolution, vol. 17, no. 6, pp. 368-376, 1981.

[109] A. Rzhetsky and M. Nei, "A simple method for estimating and testing minimum-evolution trees," Molecular Biology and Evolution, vol. 9, no. 5, pp. 945-967, 1992.

[110] J. P. Huelsenbeck, F. Ronquist, R. Nielsen, and J. P. Bollback, "Bayesian inference of phylogeny and its impact on evolutionary biology," Science, vol. 294, no. 5550, pp. 2310-2314, 2001.

[111] J. Felsenstein, "Confidence limits on phylogenies: an approach using the bootstrap," Evolution, vol. 39, no. 4, pp. 783-791, 1985.

[112] M. Hasegawa, H. Kishino, and T. Yano, "Dating of the humanape splitting by a molecular clock of mitochondrial DNA," Journal of Molecular Evolution, vol. 22, no. 2, pp. 160-174, 1985.

[113] K. Katoh, K. Kuma, H. Toh, and T. Miyata, "MAFFT version 5: improvement in accuracy of multiple sequence alignment," Nucleic Acids Research, vol. 33, no. 2, pp. 511-518, 2005.

[114] A. Dereeper, S. Audic, J. Claverie, and G. Blanc, "BLASTEXPLORER helps you building datasets for phylogenetic analysis," BMC Evolutionary Biology, vol. 10, no. 1, article 8, 2010.

[115] A. Dereeper, V. Guignon, G. Blanc et al., "Phylogeny.fr: robust phylogenetic analysis for the non-specialist," Nucleic Acids Research, vol. 36, pp. W465-W469, 2008.

[116] J. Castresana, "Selection of conserved blocks from multiple alignments for their use in phylogenetic analysis," Molecular Biology and Evolution, vol. 17, no. 4, pp. 540-552, 2000.

[117] K. Tamura, "Estimation of the number of nucleotide substitutions when there are strong transition-transversion and G+Ccontent biases," Molecular Biology and Evolution, vol. 9, no. 4, pp. $678-687,1992$. 
[118] J. P. Huelsenbeck and F. Ronquist, "MRBAYES: bayesian inference of phylogenetic trees," Bioinformatics, vol. 17, no. 8, pp. 754-755, 2001.

[119] F. Ronquist and J. P. Huelsenbeck, "MrBayes 3: bayesian phylogenetic inference under mixed models," Bioinformatics, vol. 19, no. 12, pp. 1572-1574, 2003.

[120] J. A. A. Nylander, MrModeltest v2. Program Distributed by the Author, Evolutionary Biology Centre, Uppsala University, 2004.

[121] P. Legendre and V. Makarenkov, "Reconstruction of biogeographic and evolutionary networks using reticulograms," Systematic Biology, vol. 51, no. 2, pp. 199-216, 2002.

[122] V. Makarenkov, "T-REX: reconstructing and visualizing phylogenetic trees and reticulation networks," Bioinformatics, vol. 17, no. 7, pp. 664-668, 2001.

[123] V. Makarenkov, "An algorithm for the fitting of a tree metric according to a weighted least-squares criterion," Journal of Classification, vol. 16, no. 1, pp. 3-26, 1999.

[124] A. Rocha-Olivares, J. W. Fleeger, and D. W. Foltz, "Decoupling of molecular and morphological evolution in deep lineages of a meiobenthic harpacticoid copepod," Molecular Biology and Evolution, vol. 18, no. 6, pp. 1088-1102, 2001.

[125] B. W. Frost and A. Bucklin, "Morphological and molecular phylogenetic analysis of evolutionary lineages within Clausocalanus (Copepoda: Calanoida)," Journal of Crustacean Biology, vol. 29, no. 1, pp. 111-120, 2009.

[126] T. A. Heath, S. M. Hedtke, and D. M. Hillis, "Taxon sampling and the accuracy of phylogenetic analyses," Journal of Systematics and Evolution, vol. 46, no. 3, pp. 239-257, 2008.

[127] J. Bergsten, "A review of long-branch attraction," Cladistics, vol. 21, no. 2, pp. 163-193, 2005. 

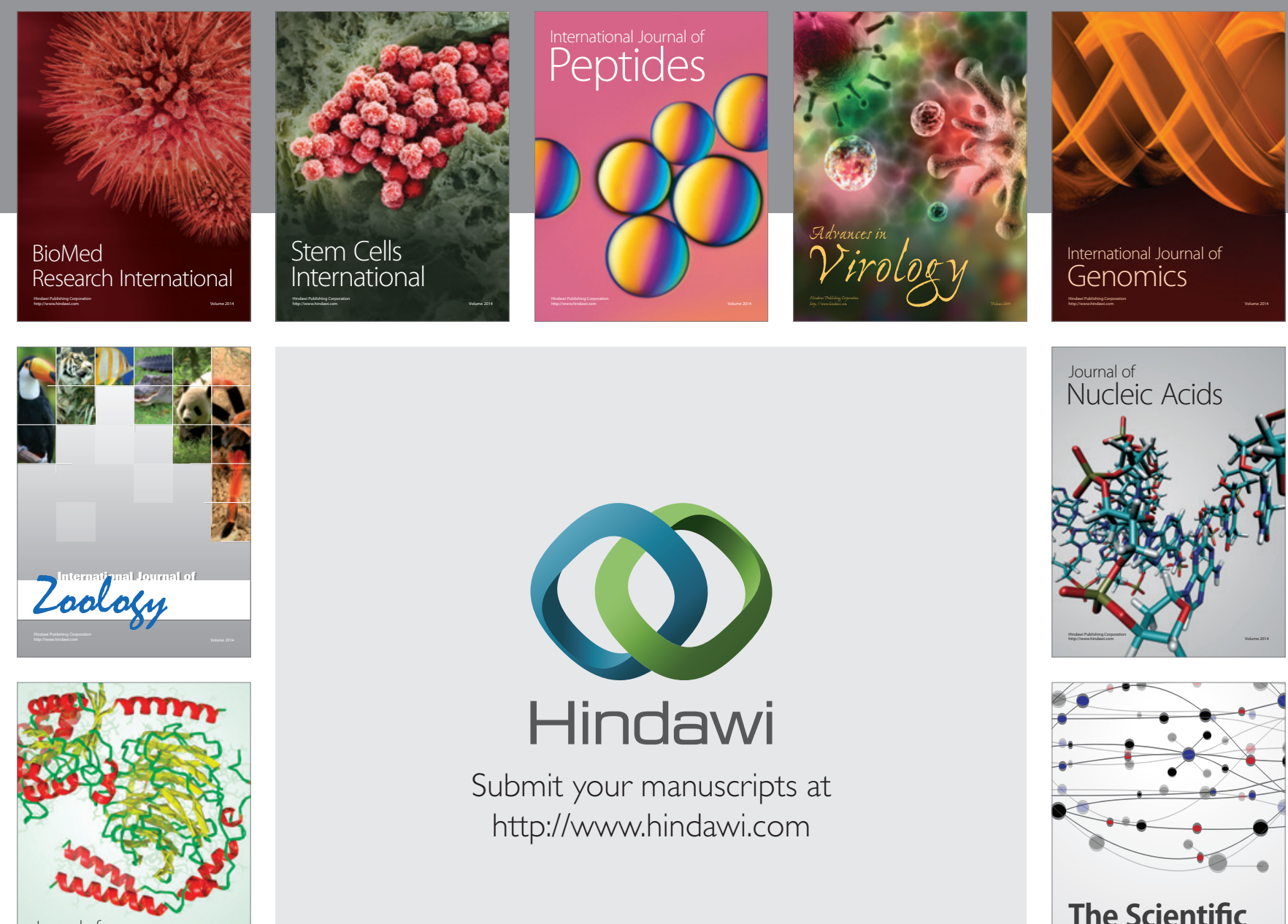

Submit your manuscripts at

http://www.hindawi.com

Journal of
Signal Transduction
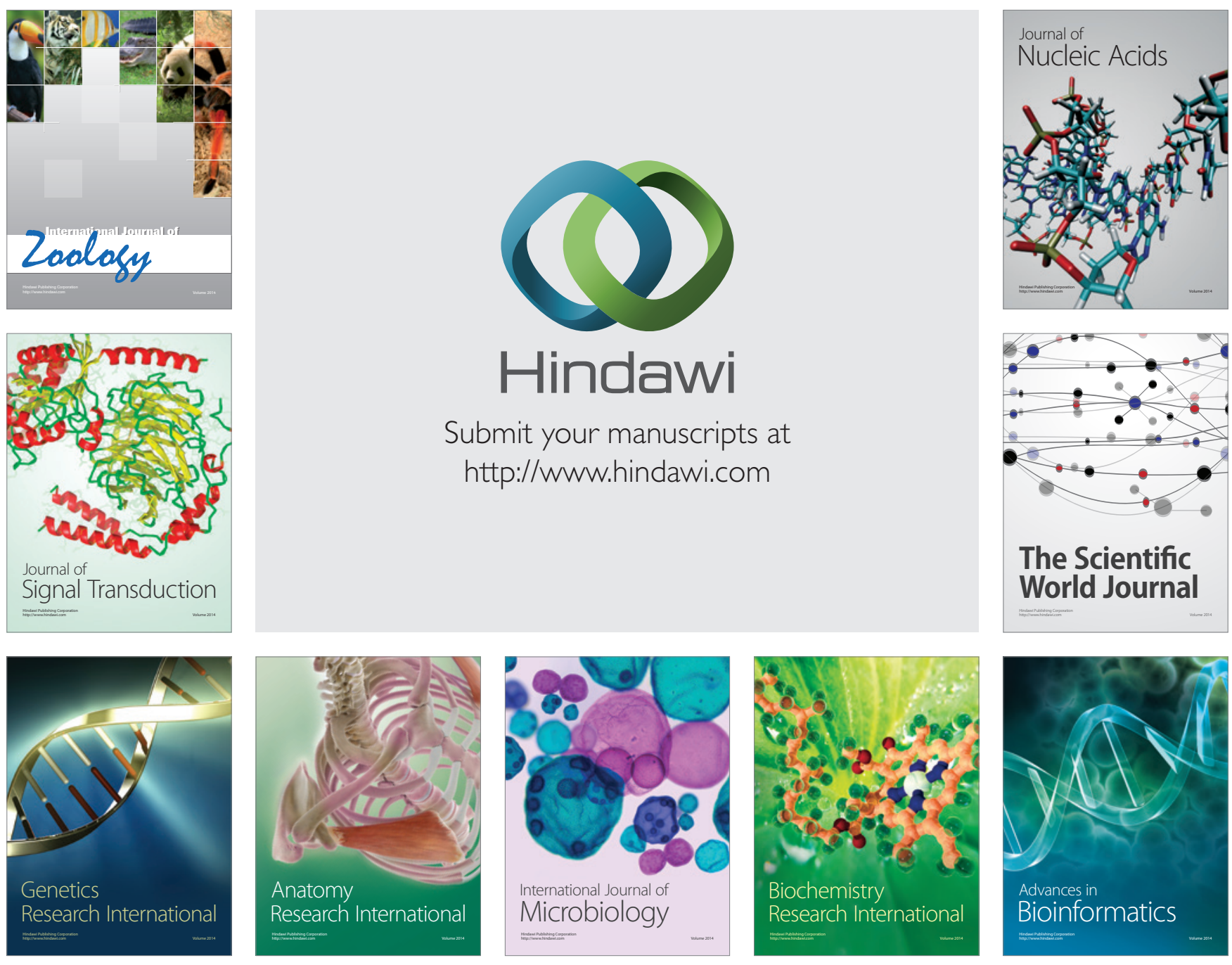

The Scientific World Journal
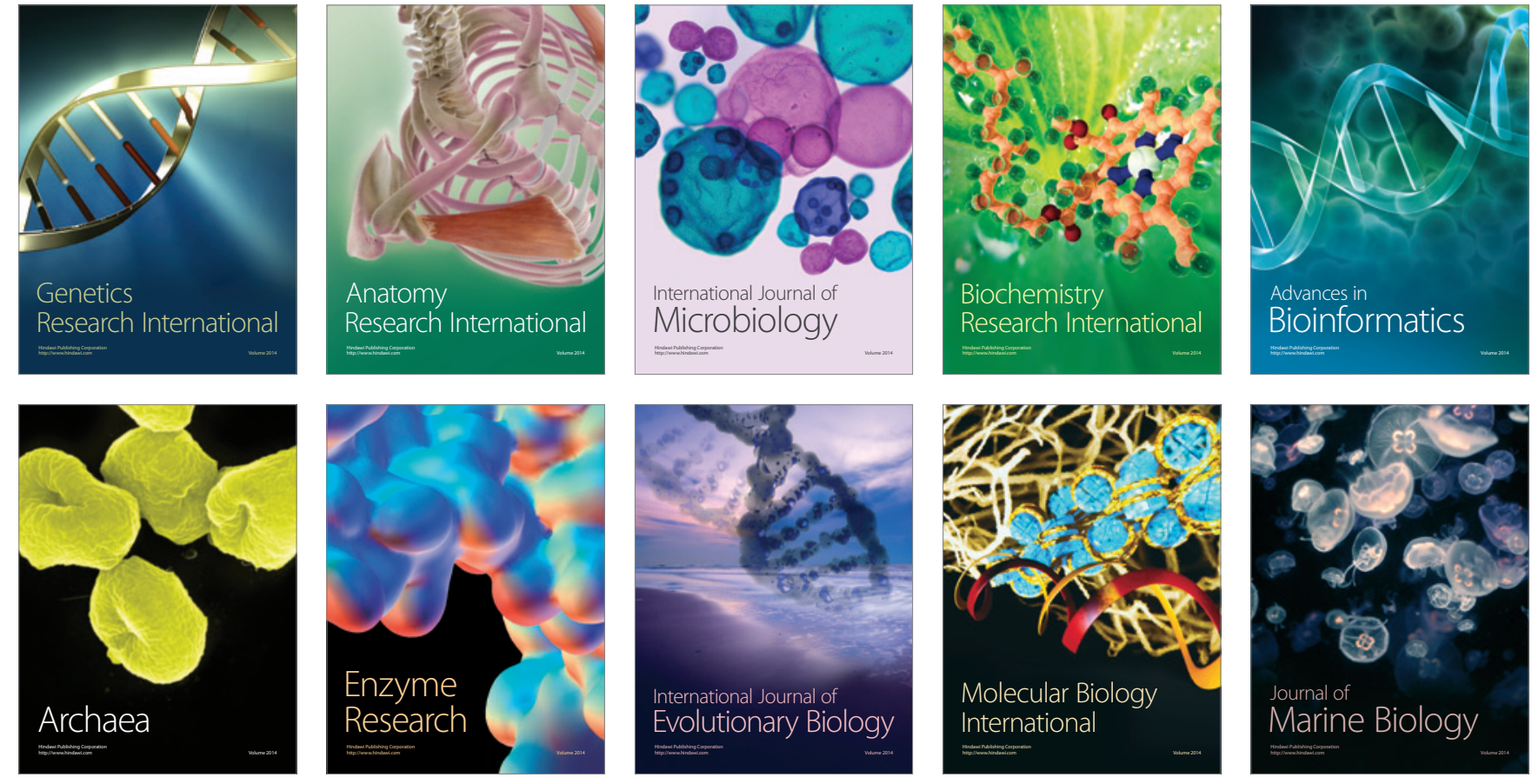